\title{
Relasi Gender dalam Pernikahan Keturunan Sayyid di Desa Cikoang Kabupaten Takalar; Studi Kasus Perbandingan Hukum Islam Dan Hukum Adat
}

\author{
Adriana Mustafa, Arwini Bahram \\ Universitas Islam Negeri (UIN) Alauddin Makassar \\ Adrinamustafa71@gmail.com, arwinib@gmail.com \\ Abstrak
}

Hukum Islam berpandangan bahwa konsep kafaah dilihat dari berbagai aspek, yaitu agama, keturunan, harta, dan paras. Di antara keempat hal tersebut, syariat mengutamakan agama sebagai tolok ukur pokok dalam menentukan konsep kafaah. Hukum adat memandang bahwa pernikahan keturunan sayye dalam masyarakat yang masih mempertahankan nilai-nilai keturunan, sistem dan kepercayaan mereka terhadap keturunan dari nabi Muhammad saw. merupakan aturan yang sudah menjadi mutlak dan tidak ada yang dapat mengubahnya. Sistem pernikahan menjadi problem tersendiri karena dapat mengucilkan kaum perempuan, dan pembatasan hak-haknya sebagai perempuan. Tujuan dari penelitian ini untuk menilik dan menelusuri seluk-beluk dari lahirnya sistem pernikahan sayye yang melahirkan relasi gender di kalangan masyarakat penganut pernikahan sayye. Metode penelitian yang digunakan adalah penelitian lapangan (field research) dan bersifat kualitatif dan komparatif. Sumber data yang dipergunakan dalam penelitian ini bersumber dari data primer dan sekunder. Hasil penelitian ini adalah bahwa bentuk relasi gender pernikahan keturunan sayye memiliki perbedaan dalam menentukan kehidupan pernikahannya.

Kata Kunci: Relasi Gender; Pernikahan; Keturunan Sayye.

Abstract

Islamic law holds that the concept of kafaah comes from various aspects, namely religion, descent, property, and face. Among these four things, Sharia prioritizes religion as the main yardstick in determining the concept of kaffah. On the other hand, customary law views that the marriage of sayye descendants in a society still maintains their familiarity, system and belief in the descendants of the Prophet Muhammad. rules that have become absolute and nothing can be seen. However, the marriage system becomes a problem because it can exclude women, and their rights as women. The purpose of this study was to examine and trace the ins and outs of the Sayye marriage system so that gender relations were born among the Sayye community. The research method used is field research and is qualitative and comparative. Sources of data used in this study come from primary and secondary data. The result of this research is that the form of Sayyid's marriage gender relation has the right to determine in his life.

Keywords: Gender Relations, Marriage, Sayye's Descendants

\section{Pendahuluan}

Penciptaan manusia di muka bumi ini adalah untuk menjadi hamba yang tunduk dan patuh serta mengabdi kepada Allah swt. juga untuk menjadi khalifah di bumi Allah swt telah menciptakan segala sesuatunya secara adil dan sesuai dengan kodratnya. Begitupun dengan manusia, Allah menciptakan manusia dengan kodratnya berdasarkan keistimewaan dan kekurangan yang terdapat pada laki-laki dan perempuan. Allah memang menciptakan laki-laki dan perempuan dengan perbedaan kodrat, namun perbedaan kodrat tersebut seharusnya tidak lantas membuat kedudukan wanita dalam Islam berada jauh dibawah laki-laki dan laki-laki tidak 
berhak berperilaku kasar, ataupun senonok pada wanita. setiap manusia memiliki kedudukan yang sama dihadapan Allah, yang membedakannya hanya pada letak derajat ketakwaannya. Allah swt. menciptakan manusia dari jenis laki-laki dan perempuan kemudian manusia dikumpulkan menjadi berbangsa-bangsa dan bersuku-suku agar saling kenal-mengenal. Sesungguhnya yang paling mulia di sisi Allah swt. adalah yang paling bertakwa. ${ }^{1}$

Salah satu tujuan penciptaan manusia dari jenis laki-laki dan perempuan adalah agar mereka dapat berhubungan satu sama lain dalam kedamaian, saling mencintai dan menghasilkan keturunan. ${ }^{2}$ Satu-satunya cara yang Allah swt. pilihkan kepada hamba-Nya untuk menghasilkan keturunan dan berkembang biak adalah dengan pernikahan. ${ }^{3}$

Pernikahan berasal dari kata nikah yang artinya menurut bahasa yaitu akad atau wathi ${ }^{4}$ Pernikahan bertujuan untuk menciptakan kehidupan keluarga antara laki-laki sebagai suami dan perempuan sebagai istri, anak-anak serta orang tua yang aman, tentram, saling mencintai (mawaddah) dan saling menyantuni (warahmah). ${ }^{5}$

Pernikahan tidak hanya menyangkut tentang pihak laki-laki atau pihak perempuan saja, akan tetapi menyangkut kedua belah pihak dalam mewujudkan kehidupan yang lebih baik. Relasi antara laki-laki dan perempuan dapat dikatakan berjalan dengan baik jika keduanya dapat menjalankan perannya sesuai dengan fungsinya masing-masing sesuai dengan kesepakatan bersama antara pihak laki-laki dan perempuan. ${ }^{6}$

Indonesia sebagai salah satu negara yang menganut sistem masyarakat patriarki yang di dalamnya menyimpan tiga ideologi dasar tentang status laki-laki dan perempuan dalam struktur sosial masyarakat. Pertama, manusia pertama adalah laki-laki, dan perempuan diciptakan dirinya sehingga ia adalah makhluk sekunder. Kedua, walaupun perempuan adalah makhluk kedua dalam proses penciptaan, ia adalah makhluk pertama dalam membuat dosa, dialah yang menggoda Adam sehingga akhirnya terusir dari surga. Ketiga, perempuan bukan hanya dari laki-

\footnotetext{
${ }^{1}$ Sukarni, "Eksistensi Sistem Pernikahan Anak Perempuan Sayyid Di Desa Cikoang Kecamatan Angarabombang Kabupaten Takalar: Perspektif Komunikasi Budaya", Skripsi (Fakultas Dakwah dan Komunikasi Uin Alauddin Makassar, 2017), h.3.

${ }_{2}^{2}$ Abdul Rahman, Perkawinan Dalam Syariat Islam (Jakarta: Pt. Rhineka Cipta, 1996), h. 1.

${ }^{3}$ Sayyid Sabiq, Fiqh Sunnah 6, (Bandung: al-Ma'arif, 1980), h. 7.

${ }^{4}$ Djaman Nur, Fikih Munakahat (Semarang: Dina Utama Semarang, 1993), h. 2.

${ }^{5}$ Sayuti Thalib, Hukum Kekeluargaan Indonesia (Jakarta: Ui Press, 1974), h. 47.

${ }^{6}$ Komariyah, "Tradisi Ayam Anggrem: Studi Tentang Relasi Gender Dalam Kehidupan Perkawinan Msyarakat Desa Tugu Kabupaten Indramayu, Skripsi (Fakultas Ilmu Sosial Universitas Negeri Semarang, 2005), h. 2-3
} 
laki, tetapi juga untuk laki-laki. Asumsi ketiga ini berimplikasi pada munculnya anggapan bahwa perempuan tidak mempunyai hak untuk mendefinisikan status, hak dan martabatnya, kecuali apa yang telah disediakan kaum laki-laki untuknya. Kehadiran perempuan di dunia ini bersifat instrumental bagi kepentingan laki-laki bukan fundamental. ${ }^{7}$

Sulawesi Selatan sebagaimana dengan daerah-daerah lainnya di Indonesia cukup kaya dengan unsur-unsur budaya seni dan tradisi, baik budaya material maupun budaya spiritual. Salah satu tradisi masyarakat yang berkaitan dengan relasi gender mengenai peran dan fungsi laki-laki dan perempuan dalam pernikahan yaitu terdapat pada Desa Cikoang Kabupaten Takalar yang masih sangat kental dengan adat dan budayanya.

\section{Pembahasan}

\section{Sejarah Keberadaan Keturunan Sayyid}

Kehadiran kaum sayyid di desa Cikoang tidak lepas dari keberadaan golongan sayyid di Hadramaut. Hadramaut adalah sebuah daerah kecil yang ada di Arab Selatan. Hadramaut merupakan daerah pantai di antara desa-esa nelayan dan sebagia daerahnya pegunungan. Di sepanjang pantai hanya terdapat buit-bukit atau daratan tinggi yang sangat luas. Pemandangannya di sepanjang jalan terlihat gersang,banyak di jumpai padang rumput dan pohon berduri. Munculnya Sayyid di desa Cikoang berhubungan dengan kedatangan Sayyid Jalaluddin menyebarkan agama Isam.Namun, sebeum kedatangan Sayyid Jalaluddinstrata sosial masyarakat Makassar adalah Karaeng (kalangan hamba sahaja). Setelah Jalaluddin memperkenalkan Islam di desa Cikoang, kedudukan paling tinggi dalam masyarakat Cikoang di duduki oleh kalangan Sayyid.

Sayyid Jalaluddintiba di daerah Laikang pada sebuah perkampugan di tepi pantai yang bernama Cikoang. Setelah menempuh perjalanan melalui laut dari Gowa. Perkampungan itu di samping terletak di muara sungai yang cukup luas dan dalam, sehingga perahu-perahu besar dapat berlabuh di sana. Kedatangan Sayyid Jalaudding pada tahun awal abad ke 17 Masehi. Di daerah Mangarabombang Sayyid Jalaluddin merasa sangat di sambut dengan baik oleh masyarakat. Beliau mengadakan pengajian agama Islam berbagi macam ilmu fikih, ilmu tasawuf,

\footnotetext{
${ }^{7}$ Siti Musdah Mulia, "Kekerasan terhadap Perempuan Mencari Akar Kekerasan dalam Teologi”, SAWWA Jurnal Studi Gender,(Semarang: PSG IAIN Walisongo, 2008), h. 12-13.
} 
dan maulid Nabi Muhammad saw. Berselang beberapa lama berdiam di Mangarabombang Sayyid Jalaluddin merasa usianya telah lanjut.

Sayyid Jalaluddin menyebarkan agama Islam degan membawa ketiga anaknya yang bernama Sayyid Umar, Sayyid Sahabuddin dan Sayyidah Saribanong dan pernikahannya dengan I Acara Daeng Tamami. Dari ketiga anak keturunan Sayyid Jalaluddin, hanya Sayyid Umar dan Sayyid Sahabuddin yang sempat menikah dan memperoleh anak keturunan sedangkan Sari banong tidak sempat menikah karena telah meninggal sewaktu dewasa. Lewat keturunan Sayyid Jalaluddin inilah pengajaran-pengajaran yang diajarkan oleh Saayid Jalaluddin diteruskan dari waktu ke waktu sampai sekarang tradisi dan kebudayaannya itu masih bertahan.

Dalam sejarah perkembangan Islam di Cikoang, tidak bisa dilepas dari masyarakat Sayyid Jalluddin yang berhasil menyebarkan agama Islam daerah tersebut. Sebelum masuknya agama Islam di Sulawesi Selatan, penduduk asli suku Makassar telah menganut kepercayaan Animisme dan Dinamisme. Kepercayaan animisme mengarah kepada penyembah roh nenek moyang yang mereka anggap bersemayam di batu-batu besar dan tempat-tempat dianggap keramat, kepercayaan dinamisme diwujudkan dengan cara menyembah kepada kekuatan alam atau benda-benda sepeti gunung, batu dan benda-benda lainnya yang disaklarkan.

Setelah menjadi penganut Islam, perlahan-lahan meninggalkan kepercayaan alam akan tetapi bagi masyarakat yang hidup di desa-desa belum dapat meninggalkan, sepenuhnya unsurunsur kepercayaan alam yang bersumber dari warisan nenek moyang. Dalam kehidupan seharihari, adat dan radisi tetap diwarnai oleh unsur kepercayaan lama, penganut isalam mayoritas orang-orang alam yang tidak memahami secara jelas ajaran Islam.

Dengan reaksi positif dan keinginan yang begitu kuat dari masyarakat Cikoang pada masa iitu untuk lebih mengetahui lebih jauh tentang ajaran Islam, menandakan bahwa jalan penyebaran Islam yang dilakukan oleh Sayyid Jalaluddin memutuskan untuk tinggal di Cikoang untuk mengislamnkan orang-orang Cikoang.

\section{Gender dan Diskursus Perkawinan Sayyid}

Untuk memahami konsep gender, maka perlu dibedakan antara istilah sex dan gender karena hal ini sering kali menjadi pemabahasan yang timpang tindih. Hal ini disebabkan karena 
istilah lain "seks" berdekatan dengan konsep gender. ${ }^{8}$ Istilah seks dalam masyarakatpun bermakna ganda, terkadang istilah seks dipakai untuk menunjuk perilaku seksual seperti hubungan badan dan terkadang digunakan untuk menunjuk jenis kelamin yakni laki-laki dan perempun. ${ }^{9}$

Perbedaan seks berarti perbedaan jenis kelamin yang didasarkan pada perbedaan biologis atau bawaan yang melekat di tubuh laki-laki atau perempuan. Disebut perempuan karena memiliki sejumlah organ perempuan seperti vagina dan rahim sehingga ia bisa menyusui anaknya. Seorang anak disebut laki-laki ditandai dengan kepemilikan penis, bila telah balig ia akan memiliki kumis, cambang dan organ laki-laki lainnya. ${ }^{10}$ Pengertian gender, tidak sekedar merujuk ada perbedaan biologis semata tetapi juga perbedaan prilaku, sifat dan ciri-ciri khas yang dimiliki laki-laki atau perempuan. Lebih jauh istilah gender mengacu pada peranan dan hubungan antara laki-laki dan perempuan. Selain itu, gender juga digunakan untuk mengidentifikasi perbedaan laki-laki dan perempuan dari segi sosial budaya. Sementara seks secara umum digunakan untuk mengidentifikasi perbedaan laki-laki dan perempuan dari segi anatomi biologi. Karena itu, istilah seks lebih banyak berkonotasi pada aspek anatomi, hormonal, repreduksi tubuh sedangkan gender pada aspek sosial, budaya, phisikologis dan aspek non biologis lainnya. ${ }^{11}$ Jika istilah seks merupakan bawaan sejak lahir dan sepenuhnya kehendak Tuhan maka istilah gender sepenuhnya didasarkan atas kreasi atau ciptaan masyarakat. Karena itu, seks atau jenis kelamin tidak akan pernah berubah, berbeda dengan gender ia akan selalu mengalami perubahan dari waktu ke waktu dan tempat. ${ }^{12}$

Gender sebagai alat analis biasanya dipergunakan oleh penganut aliran ilmu sosial konflik, yang memusatkan perhatian pada ketidakadilan struktural dan sistem yang disebabkan oleh gender. ${ }^{13}$ Sebagaimana dimaksudkan oleh Oakley bahwa gender adalah perbedaan yang

\footnotetext{
${ }^{8}$ Umi Sumbulah, ddk, Spektrum Gender Kilasan Inklusi Gender di Perguruan Tinggi (Malang: UIN Malang Press, 2008), h.8.

${ }^{9}$ Siti Musda Mulya dkk, Keadilan dan Kesetaraan Gender Perspektif Islam (Cet II: Jakarta; Lembaga Kajian Agama dan Gender, 2003), h. 60.

${ }^{10}$ Nasaruddin Umar, "Perspektif Gender dalam Islam” Jurnal Paramadina, Vol. I, No. 1, Juli-Desember 1998, h. 99.

${ }^{11}$ Nasaruddin Umar, Argumen Kesetaraan Gender Perspektif Al-Qur'an (Cet. I: Jakarta; Paramadina, 1999), h. 35.

${ }^{12}$ Achmad Musyahid, “Kesetaraan Gender Perspektif Filsafat Hukum Islam” Jurnal Sipakalebbi, Vol. I No. 1, 2013, h. 175.

${ }^{13}$ Mansour Fakih, Analisis Gender \& Taransformasi Sosial (Cet. V: Yogyakarta; Pustaka Pelajar, 2013 ), h. 8.
} 
bukan biologis dan bukan kodrat Tuhan. Perbedaan gender adalah behavioral differences antara laki-laki dan perempuan yang socially constructed, yakni perbedaan yang bukan kodrati melainkan diciptakan oleh kaum lelaki dan perempuan melalui proses sosial dan budaya yang panjang. Ditambahkan oleh Caplan dalam bukunya The Cultural Construction of Sexuality karena pengaruh sosial dan budaya atau kultural tersebut, gender dapat berubah dari waktu ke waktu, suatu tempat ke tempat yang lain, atau bahkan dari tingkat atau kelas tertentu dalam masyarakat. $^{14}$

Perbedaan gender sesungguhnya tidaklah menjadi masalah sepanjang tidak melahirkan ketidakadilan gender atau gender inequalities. Namun yang menjadi persoalan adalah pada kenyataannya perbedaan gender telah melahirkan berbagai ketidakadilan, baik bagi kaum lakilaki maupun kaum perempuan. Ketidakadilan gender merupakan sistem dan struktur di mana kaum laki-laki dan perempuan menjadi korban dari sistem tersebut. Ketidakadilan gender tersebut dapat dilihat dalam berbagai bentuk, seperti marginalisasi atau proses pemiskinan ekonomi, subordinasi atau anggapan tidak penting dalam pengambilan keputusan, pembentukan stereotipe atau melalui pelebelan negatif, kekerasan serta sosialisasi ideologi nilai peran gender. ${ }^{15}$ Manifestasi ketidakadilan gender tidak dapat dipisahkan, karena baik yang satu dengan yang lain saling berkaitan dan saling mempengaruhi secara dialektis. Misalnya marginalisasi ekonomi kaum perempuan justru terjadi karena stereotipe tertentu atas kaum perempuan dan hal tersebut menyumbang pada subordinasi, kekerasan kaum perempuan yang akhirnya tersosialisasikan dalam keyakinan, ideology dan visi kaum perempuan itu sendiri.

Perbedaan pandangan dalam gender jika dilihat dari pembahasan subordinasi kaum muslimah, misalnya keyakinan tentang laki-laki "qawwam” (laki-laki mempimpin kaum perempuan). Keyakinan ini mengantarkan pada pemahaman bahwa kaum perempuan adalah subordinasi dari kaum laki-laki meskipun secara objektif ia lebih mampu, lebih pandai, dan lebih layak. Keadaan yang demikian, mengakibatkan tafsiran agama serasa melahirkan ketidakadilan. Dari hal tersebut, hal yang ingin disampaikan sebenarnya adalah tafsiran agama telah melahirkan peran gender (gender role) yang sesugguhnya lahir dari konstruksi sosial yang ditetapkan

\footnotetext{
${ }^{14}$ Mansour Fakih, Posisi Kaum Perempuan dalam Islam: Tinjauan Analisis Gender (Tarjih, Edisi 1 Desember 1996), h. 26.

${ }^{15}$ Mansour Fakih, Analisis Gender \& Konstruksi Sosial, h. 12-13.
} 
berdasarkan keyakinan atau tafsiran agama antara laki-laki dan perempuan. Selain subordinasi tersebut, marginalisasi kaum perempuan dapat kita jumpai dalam kehidupan sehari-hari yang lain, misalnya dalam hal urusan keluarga. ${ }^{16}$ Bentuk-bentuk ketidakadilan bisa berupa kawin paksa dan perceraian secara sepihak tanpa mempertimbangkan istri, eksploitasi perempuan sebagai objek seksual. ${ }^{17}$ Hal ini terjadi dalam bentuk diskriminasi atas anggota keluarga yang laki-laki dan perempuan, termasuk dalam hal kesempatan perempuan dalam menentukan pilihan untuk dirinya sendiri atau dalam penentuan pemilihan pasangan. Marginalisasi ini diperkuat oleh adat istiadat yang telah tumbuh dan mendarah daging khususnya pada masyakat tertentu. ${ }^{18}$ Padahal, dalam hal pernikahan pada dasarnya melibatkan banyak pihak, tidak hanya melibatkan antara orang tua atau wali, akan tetapi pelibatan kedua belah pihak termasuk perempuan itu sendiri sebagai posisi yang akan dilamar. Namun ketimpangan yang terjadi adalah orang tua tidak mendiskusikan hal tersebut atau tidak meminta pendapat kepada perempuan atau anak yang bersangkutan.

\section{Tradisi Pernikahan Sayyid dan Starategi Mempertahankan Nasab}

Indonesia adalah Negara kepulauan yang terletak di anata samudra fasifik dan samudra Hindia. Penduduk yang berdiam yang berasal dari pulau-pulau itu beraneka ragam adat budaya dan hukum adatnya. Hal itu terjadi karena menurut sejarah, perkembangan budayanya zaman indonesia, pergaulan hidup, tempat kediaman dan lingkungan alam tempat tiggalnya berada. ${ }^{19}$

Demikian pula halnya, adat pernikahan anatara masyarakat yang satu berbeda dengan masyarakat yang lainnya, antara suku bangsa yang satu berbeda dengan suku bangsa yang lainnya, begitu pula antara masyarakat desa berbeda dengan masyarakat kota. Karena itu, penulis bermaksud menelusuri tradisi pelaksanaan sistem pernikahan anak perempuan Sayyid di Desa Cikoang Kecamatan Mangarabombang Kabupaten Takalar.

Strategi yang dilakukan Masyarakat Sayyid dalam Tradisi sistem pernikahan Sayyid untuk menjaga identitas seorang Sayyid, maka para Sayyid harus menjaga Nasab Nabi Muhammad saw dimana perempuan Sayyid tidak boleh menikah deangan kaum pria diluar

\footnotetext{
${ }^{16}$ Mafudah Ch, Psikologi Keluarga Islam Berwawasan Gender (Malang: UIN Malang Press, 2008), h. 11.

${ }^{17}$ Febri Yuliani, "Pengaruh Partisipasi Masyarakat terhadap Upaya Penghapusan Kekerasan dalam Rumah Tangga di Kota Pekanbaru” Spirit Publik, Vol. 4, No. 2, 2008, h. 131.

${ }^{18}$ Mansour Fakih, Analisis Gender \& Transformasi Sosial, h.17.

${ }^{19}$ Hilman Hadikusuma, Hukum perkawinan adat (Bandung:PT.Citra Aditya Bakti,1990).h
} 
komunitasnya. Dalam hal ini adalah aturan yang tidak tertukis yang dipahami oleh keturunan Sayyid di Desa Cikoang.

"Menurut Syarifah Sriyanti, aturan dalam sistem pernikahan Sayyid memang tidak boleh dilanggar, karena aturan sudah ada sejak nenek moyang, walaupun saya pribadi meyukai seorang laki-laki diluar komunitas maka, saya akan membatasi dan tahu diri kalau kita punya batasan, maka rasa suka terhadap laki-laki bukan sekeurunan maka harus dibatasi juga". ${ }^{20}$

Dilihat dari sistem pernikahan anak perempuan Sayyid, ternyata hal yang dilakukan agar sisitem pernikahan ini tidak terjadi pemutusan nasab, maka strata Sayyid dan Syarifah menurut prioritas utama bagi Sayyid dalam memilih jodoh atau menikahkan putra putri dengan tujuan agar keturunan mereka tidak terputus (nasabnya). Faktor nasab ini berperan lebih dalam kehidupan perkawinan di masyarakat Sayyid.

Strategi bagi masyarakat Sayyid agar tradisi perepuan ini masih bertahan,ada dua macam antara lain:

a. Sayyid mencari jodoh, ada ada dua pencarikan jodoh. Pertama, pilihan orang tua. Usia yang ideal bagi putri Sayyid yang di sebut Syarifah untuk menikah adalah 20-25 tahun. Jika usia Syarifah telah mencapai 25 tahun, tapi belum juga menemukan jodoh maka keluarga sibuk mencari pasangan yang cocok bagi Syarifah tersebut. Kedua, pilihan sendiri dengan persetujuan orang tua. Tentu saja jodoh diutamakan adalah seorang Syarifah. Perjodohan hingga masih terjadi di komunitas Sayyid, penjelasan tentang pentingnya menjaga nasab telah ditanamkan sejak kecil kepada anak-anaknya agar nanti sudah tumbuh dewasa kecintaan terhadap sesama.

b. Didikan, sejak kecil mereka di didik dibrikan pemahaman pengtahuanpengetahuan tentang kebiasaan mereka yang lain dari pada yang lain, serta akibat jika melanggar ketentuan yang telah di atur oleh adat mereka.

\section{Pernikahan Sayyid dalam Pandangan Hukum Islam dan hukum Adat}

Bangsa Arab pada saat ini adalah bangsa yang paling banyak di salah pahami penggambaran keadaan yang serba buruk tentang orang-orang Arab sbelum Islam membuat seolah-olah semakin tingginya pihak-pihak yang membut gambaran negatif tentang orang-orang Arab dalam mengagungkan Nabi Muhammad saw. Hal ini merupakan tanggung jawab kesalahan kepada para penulis sejarah yang menuduh dan memberikan gambaran yang buruk tentang

${ }^{20}$ Syarifah Sriyanti, (30 Tahun), “Wawancara” Desa Cikoang, tanggal 01 Juni 2019 
orang-orang Arab yang ditimbulkan oleh golongan Syu'ubiah yaitu golngan orang-orang muslim bukan Arab.

Kebencian terhadap orang Arab telah diprediksi oleh Nabi Muhammad saw. kepada sahabatnya yang berasal dari bangsa Persia yaitu Salman Al Farisi. Rasulullah saw bersabda yang Artinya; "Wahai Salman, janganlah membenciku, nanti engkau akan berpisah dengan agamamu. Saya (Salman) berkata: Wahai Rasulullsah bagaimana saya membenci engkau yang memberiku hidayah Allah swt. Berkata Rasulullah saw: Jika engkau membenci Arab maka engkau juga membenciku' ${ }^{21}$

Akan tetapi dengan berbagi dalih dan argumentsi kaum Syu'ubiah tidak henti-hentinya mengkampanyekan permusuhan terhadap bangsa Arab dengan berbagai cara salah satunya yaitu dengan ide kesataraan atau persamaan mereka berkata bahwa Allah swt telah menciptakan manusia berbangsa-bangsa dan bersuku-suku tidak ada bangsa atau suku yang paling mulia kecuali karna takwanya. Allah swt berfirman dalam al-Qur'an QS. Al-Hujurat/49:13.

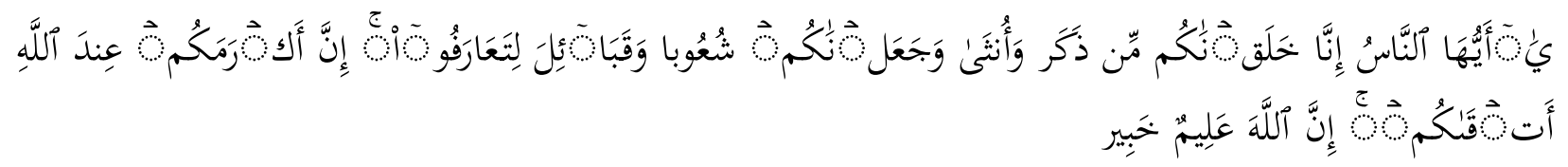

Terjemahnya:

"Wahai manusia, sesungguhya kami jadikan kalian dari jenis laki-laki dan perempuan dan kami jadikan kalian berbangsa-bangsa dan berkabilah-kabilah untuk saling mengenal.

Sesungguhnya orang-orang yang paling mulia di antara kalian ialah yang besar takwanya."

Semua orang memang tidak ada perbedaaan baik itu kulit, kaya atau miskin, merdeka atau budak, keculi dilihat dari sisi takwa. Akan tetapi perlu diperhatikan, kata 'paling muliah' dan 'paling bertaqwa' pada ayat di atas tidak bermakna banyak orang akan tetapi satu orag saja. Diantara manusia yang bertqwa maka Rasulullah saw adalah manusia yang paling bertaqwa yang tidak dapat menyamainya.

Silsilah dari nabi Muhammad saw merupakan silsilah yang mempunyai keutamaan diantara silsilah manusia lainnya. Tidak ada seorang pun yang sederajat diantara manusia dalam hal perkawinan dengan keluarganya. Imam Al Sayuthi dalam kitabnya yang berjudul Al Khosois berkata: Daripada kekhususan Rasulullah saw bahwasanya tidak ada satupun manusia yang pantas atau sekufu unuk meikah dengan keluarga Rasululah saw.

\footnotetext{
${ }^{21}$ Hizbut Tahrir, Pilar-Pilar Pengokoh Nafsiah Islamiyah (Cet. I; Jakarta: Ustka Fikrul Islam, 2004), h. 43.
} 
Adapun keluarga atau Keturunan nabi muhammad saw. Melalui hasan bin ali dan husain bin ali di Indonesia dikenal dengan gelar sayye (sayyid). Salah satu tempat penyebaran sayye di Indonesia yaitu di desa cikoang. Hukum perkawinan sayye di cikoang tetap memegang teguh aturan yang menjaga kemurnian nasab dari Rasulullah. Dimana seorang perempuan atau syarifah dari keturunan sayye tersebut tidak dapat menikah diluar dari keturunan sayye (sekufu).

Keturunan sayye meyakini bahwa keturunannyalah yang memiliki kemuliaan dan ketaqwaan yang paling tinggi. Oleh sebab itu, keturunan sayye sangat menjaga kemuliaan keturunanya dengan tidak sembarang menikah dengan orang yang bukan segolongannya. Dalam perhitungan jenis kelamin golongan sayye, jumlah perempuan lebih banyak di bandingkan dengan laki-laki. Oleh karena itu dalam menentukan pilihan atau jodoh, keturunan sayye kerap melakukan perjodohan. Akan tetapi perjodohan akan terwujud apabila kedua belah pihak (lakilaki dan perempuan) setuju dengan perjodohan tersebut tanpa unsur paksaan. Adapun salah satu konsekuensi dari cara perjodohan tersebut yaitu adanya syarifah yang tidak mendapatkan kesempatan untuk melakukan perjodohan dengan terbatasnya jumlah laki-laki dari keturunan sayye dan usia menunggu. Akibanya banyak syarifah yang menjadi perawan tua. Namun hal ini tidak menjadi masalah bagi syarifah perawan tua, karena bagi mereka meninggal dalam keadaan mempertahankan kemuliaan dengan tidak menikah dengan laki-laki di luar golongan sayye, akan mendapatkan balasan yaitu surga.

Namun tidak menutup kemungkinan adanya syarifah yang menikah dengan laki-laki diluar sayye. Faktor seorang syarifah menikah di luar sayye yaitu karena dorongan nafsunya dan tidak medapatkan kesempatan untuk melakukan perjodohan. Akibat dari pernikahan seorang syarifah dengan seorang laki-laki yang bukan sayye ialah terbuang dari keluarga dan dianggap bukan lagi dari golongan keturunan sayye.

Salah satu metode yang telah digunakan untuk menggali data dalam penelian ini adalah observasi melalui wawancara langsung. Metode ini digunakan untuk mengamati bagaimana bentuk relasi gender penikahan keturunan Sayyid di Desa Cikoang Kabupaten Takalar.

Melihat dari sisitem pernikahannya, wawancara kemudian dilanjutkan mengenai kepatuhan komunitas Sayyid terhadap aturan yang dibuat berdasarkan pada keyakinan sebagai ahlulbait. Beberapa alasan komunitas atas aturan adat yang dibuat berdasaran atas: 
a. Telah digsriskan bahwa semua anak cucu Adam terputus nasabnya di hari kemudian. Hanya nasab Nabi Muhammad saw yang tidak akan terputus nasabnya di hari kemudian, kecuali anak cucunya sendiri yang memutuskan. Nasab itu terputus apabila para Syarifah menikah dengan seseorang yang bukan Sayyid. Pernikahan semacam ini dianggap haram hukumnya dalam kehidupan komunitas Sayyid.

b. Didasarkan pada nasab Fatimah bahwa haram hukumnya nasab Fatimah dengan nasab Adam dan cucunya tercipta dari tanah. Nabi Muhammad saw dan keturunannya dianggap suci karena Muhammad beralih ke Fatiamah, nasab diturnkan ke Hasan dan Husein, selanjutnya nasab itu beralih secara turun temurun sampai kepada Sayyid Jalaluddin. ${ }^{22}$

Selanjutnya hadist Rasulullah yang memberikan dasar pelaksanaan kafaah nasab Syarifah ini adalah hadist tentang peristiwa pernikaha Siti Fatimah dengan Ali bin Abi Thalib, sebagaimana diketahui bahwa mereka berdua adalah manusia suci yang telah dinikahkan Rasulullah saw, yang artinya:

"Sesungguhnya aku hanya seorang manusia biasa yang kawin dengan kalian dan mengawinkan anak-anakku kepada kalian, kecuali pernikahan anakku Fatimah. Sesungguhnya perkawinan Fatimah adalah perintah yang diturunkan dari langit (telah ditentukan oleh Allah swt). Kemudian Rasulullah memandang kepada anak-anak Ali dan Ja'far, dan beliau berkata: "anak perempuan kami hanya menikah dengan anak laki-laki kami, dan anak laki-laki kami hanya menikah dengan anak perempuan kami." (Kitab Makarim Al-Akhlak, h. 36 no. 2)

Hadist di atas tersebut, menueurt beliau, anak-anak perempuan (syarifah) menikah dengan laki-laki (sayyid/syarif), dan begitu pula sebaliknya. Pealsanaan kafaah yang dlakukan orlleh para keluarga Sayyid didasari oleh perbuatan Rasul, yang dicontohkan dalam menikahkan anak putrinya Fatimah dengan Ali bin Abi Thalib. Hal itu ula yang mendasari para keluarga Sayydi menjaga anak putrinya untuk tetap menikah dengan laki-laki yang sekufu sampai saat ini.

Jika telah terjadi pernikahan antara Syarifah dengan laki-laki yang bukan Sayyid, maka anak keturunan selanjutnya adalah bukan Sayyid, hal itu disebabkan anak mengikuti garis ayahnya, implikasinya keutamaan serta kemuliaan yang khusu dikaruniakan Allah swt. Untuk ahlul bait dan keturunanya tidak dapat disndang oleh anak cucu keturunan seorang Syarifah yang menikah laki-laki yang bukan Sayyid. Oleh karena itu, anak perempuan keturunan Sayyid yang melakukan pelanggaran, oleh keluarga mereka dianggap tidak pernah ada/tidak pernah lahir

\footnotetext{
${ }^{22}$ Andi Muis Karaeng Tunru (30 Tahun), masyarakat Cikoang "Wawancara" di Desa Cikoang, Tanggal 01 Juni
} 2019. 
dalam kehidupan ini. Masyarakat keturunan Sayyid tetap akan mengikuti apa-apa yang telah menjadi kebiasaan lingkungan dikomunitasnya.

Akibat adanya perkawinan sayyid akan menimbulkan beberapa gelar bagi masyarakat sayyid, diantaranya sebagai berikut:

a. Sayyid - Karaeng, yang dimaksud dengan Sayyid Karaeng ialah gelar yang diberikan kepada keturunan Sayyid dari hasil perkawinan antara kelompok Sayyid dengan kelompok Karaeng. Keturunan inilah yang memiliki dua gelar sekaligus yaitu Sayyid dan Karaeng seperti hj Sayyid Karaeng Muang dan Andi Hesti Sulaeha Karang Baji.

b. Sayyid Tuan, yang dimaksud dengan Sayyid atuan ialah yang diberian kepada keturunan Sayyid hasil dari perkawinan antara laki-laki Sayyi dan perempuan Sayyid seperti Sayyid Anwar Al-Habib (Tuan Lembang)

c. Sayyid Daeng, yang dimaksud dengan Sayyid daeng pada keturunan Sayiyid hasil dari perkawinan antara seorang laki-laki Sayyid dengan perempuan daeng (orang biasa yang baik). Seperti Sayyid Maulana dg Temba.

d. Sayyid Koko, yang dimaksud dengan Sayyid koko yaitu gelar yang dierikan kepada keturunan hasil perkawinan antara laki-laki perempuan Sayyid engan laki-laki non Sayyid. Keturunan ini tidak lagi dipanggil sayyid karena hubungan darahnya dianggap telah terputus. Perniahan inilah yang dianggap sebagai pelanggaran dalam sistem pernikahan Sayyid karena memutus hubungan darah dengan keluarga.

Stigma masyarakat adat mengenai kehidupan sosial sayye melahirkan pola tersendiri dalam menentukan dengan siapa seorang sayye harus menikah, sehingga dalam menentukan status sosial masyarakat sayye digoolongkan pada dua kondisi, yaitu sebagai berikut:

1. Sayye yang Menikah Dengan Sayye

Seorang sayye yang menikah dengan sesama sayye dalam menjalani kehidupannya akan mendapakan kehidupan rumah tangga yang harmonis. Harmonis dlam artia bukan tanpa masalah dalam pernikahannya, akan tetapi setiap masalah yang di hadapi dari berbagai faktor pihak keluarga akan tetap mencari solusi dari setiap masalah yang ada. Karena tanggungjawab keterikatan hubungan nasab sebagai satu keturunan dari Nabi Muhammad saw.

2. Sayye yang Menikah Bukan dengan Keturunan dengan Sayye. 
Seorang syarifah yang menikah dengan laki-laki yang bukan dari golongan sayye, maka status dirinya bukan lagi sebagai keturunan Nabi Muhammad saw. (sayye). Akan tetapi status sosialnya mengikut kepada status sosial suaminya. Maka dari itu, jika terjadi masalah dalam pernikahannya, pihak kelurga dari syarifah tersebut tidak lagi membantu atau ikut campur dalam rumah tangganya. Sebab statusnya bukan lagi sebagai keturunan Nabi Muhammad saw. Karena sudah menjadi konsekuensi dari pernikahan yang dilakukannya.

\section{Kesimpulan}

Bentuk relasi gender pernikahan keturunan Sayyid memiliki perbedaan dalam menentukan kehidupan pernikahannya. Seorang laki-laki sayyid dibolehkan menikahi perempuan non-sayyid tanpa gelarnya sebagai sayye dihilangkan dan dianggap tidak melanggar peraturan. Sedangkan seorang syarifah tidak dibolehkan menikah dengan laki-laki diuar keturunan dari golonganya. Apabila aturan tersebut dilanggar, maka seorang syarifah tidak lagi dianggap sebagai keturunan sayyid.

\section{Daftar Pustaka}

Abdul Syatar. "TRANSFORMATION OF FIQH IN THE FORMS OF HAJJ AND ZAKAT

LEGISLATION." Mazahibuna; Jurnal Perbandingan Mazhab 1, no. 2 Desember (2019):

120-133. http://journal.uin-alauddin.ac.id/index.php/mjpm/article/view/11646.

Achmad Musyahid. "DISKURSUS MASLAHAT MURSALAH ERA MILINEAL (Tinjauan Filosofis Terhadap Konsep Maslahat Imam Malik)." Mazahibuna; Jurnal Perbandingan Mazhab 1, no. 2 (2019): 134-145.

Abdullah, Irwan. Seks, Gender dan Reproduksi Kekuasaan. Yogyakarta: Tarawang Press, 2001.

Ali, Suki. Global Feminist Politics: Identities in Changing World. New York: Routledge, 2000.

Ch, Mafudah. Psikologi Keluarga Islam Berwawasan Gender. Malang: UIN Malang Press, 2008.

-------. Paradigma Gender. Malang: Bayumedia Publishing, 2003.

Fakih, Mansour. Analisis Gender \& Taransformasi Sosial. Cet. V: Yogyakarta; Pustaka Pelajar, 2013.

-------. Posisi Kaum Perempuan dalam Islam: Tinjauan Analisis Gender. Tarjih, Edisi 1 Desember 1996.

Hilman Hadikusuma. Hukum perkawinan adat. Bandung:PT.Citra Aditya Bakti,1990.

J, Kessler Suzanne dan Wendy Mckenna. Gender: An Ethnometodological Approach. New York: John Willey \& Sons, 1997.

Kementrian Agama RI Al-Qur'an Al-Karim dan Terjemahannya. Surabaya: Halim, 2013.

Megawangi, Ratna. Membiarkan Berbeda: Sudut Baru Tentang Relasi Gender. Cet. 1; Bandung: Mizan, 1999.

Mosse, Julia Cleves. Gender dan Pembangunan. Yogyakarta: Pustaka Pelajar, 2007.

Mulia, Siti Musdah. Kekerasan terhadap Perempuan Mencari Akar Kekerasan dalam Teologi. SAWWA Jurnal Studi Gender/ Semarang: PSG IAIN Walisongo, 2008. 
-------. Keadilan dan Kesetaraan Gender Perspektif Islam. Cet II: Jakarta; Lembaga Kajian Agama dan Gender, 2003.

Musyahid, Achmad. “Kesetaraan Gender Perspektif Filsafat Hukum Islam”. Jurnal Sipakalebbi, Vol. I No. 1. 2013.

Naro, Wahyuddin, Abdul Syatar, Muhammad Majdy Amiruddin, Islamul Haq, Achmad Abubakar, and Chaerul Risal. "Shariah Assessment Toward the Prosecution of Cybercrime in Indonesia." International Journal of Criminology and Sociology 9 (2020): 572-586. https://doi.org/10.6000/1929-4409.2020.09.5

Nugroho, Riant. Gender dan Strategi Pengarus Utamanya Di Indonesia. Yogyakarta: Pustaka Pelajar, 2011.

Nur, Djaman, Fikih Munakahat. Semarang: Dina Utama Semarang. 1993.

Rahman, Abdul. Perkawinan Dalam Syariat Islam. Jakarta: PT. Rhineka Cipta, 1996.

Riant Nugroho. Gender dan Strategi Pengarus Utamanya Di Indonesia. Yogyakarta: Pustaka Pelajar, 2011.

Sabiq, Sayyid. Fiqh Sunnah 6. Bandung: al-Ma'arif, 1980.

Sihab, Umar. Hukum Islam Dan Tranformasi Pemikiran. Semarang: Dinautama, 1996.

Soepomo. Hukum Adat. Jakarta: PT Pradnya Paramita 1993.

Sumbulah, Umi ddk. Spektrum Gender Kilasan Inklusi Gender di Perguruan Tinggi. Malang: UIN Malang Press, 2008.

Thalib, Sayuti. Hukum Kekeluargaan Indonesia. Jakarta: Ui Press, 1974.

Umar, Nasaruddin. "Perspektif Gender dalam Islam” Jurnal Paramadina, Vol. I, No. 1, JuliDesember 1998.

-------. Argumen Kesetaraan Gender: Perspektif Al-Qur'an. Cet. I; Jakarta: Paramadina,1999.

Yuliani, Febri. "Pengaruh Partisipasi Masyarakat terhadap Upaya Penghapusan Kekerasan dalam Rumah Tangga di Kota Pekanbaru” Spirit Publik. Vol. 4, No. 2. 2008. 